\title{
A pesquisa on-line sobre amamentação: entre o senso comum e a OMS na era digital
}

\author{
Online breastfeeding research: between a common sense and the WHO \\ in the digital age
}

\section{La investigación online sobre la lactancia materna: entre el sentido común e la OMS en la era digital}

Marina Souto Dalmaso ${ }^{1, a}$

marina.dalmaso@hotmail.com | http://orcid.org/oooo-ooo3-3861-3980

Andrea Wander Bonamigo ${ }^{1, b}$

awbonamigo@gmail.com | http://orcid.org/oooo-0001-6435-704X

${ }^{1}$ Universidade Federal de Ciências da Saúde de Porto Alegre. Porto Alegre, RS, Brasil.

a Especialização em Atenção ao Paciente pelo Grupo Hospitalar Conceição.

${ }^{\text {b }}$ Doutorado em Saúde Pública pela Universidade de São Paulo.

\section{Resumo}

Uma vez que a internet assumiu o papel de fonte preferencial e espontânea de acesso à informação, o objetivo deste estudo é sintetizar o que as mães brasileiras buscam e encontram na internet sobre aleitamento materno, por meio de revisão crítica da literatura científica dos últimos 10 anos. Os estudos selecionados permitiram a categorização de três tópicos de discussão: qualidade das informações disponíveis; desenvolvimento de facilitadores para acesso a informações sobre aleitamento materno; e grupos virtuais de apoio à amamentação como espaço de educação em saúde. A internet é uma área com grande potencial para o desenvolvimento de ações de educação em saúde e promoção do aleitamento materno. Apesar de pertinente e atual, a literatura científica carece de pesquisas que explorem o tema do aleitamento materno sob o ponto de vista da interação on-line das mães, sendo este um campo muito rico para estudos futuros.

Palavras-chave: Aleitamento materno; Promoção da saúde; Internet; Tecnologia biomédica; Saúde Materno-infantil. 


\begin{abstract}
Since the internet has assumed the role of a preferential and spontaneous source of access to information, this work intends to synthesize what Brazilian mothers search and find on the internet about breastfeeding through a Critical Review of Literature in the last 10 years. The selected studies have allowed for the categorization of three discussion topics: quality of information available, development of facilitators for access to information on breastfeeding and virtual groups supporting breastfeeding as a space for health education. The internet is an area with great potential for the development of actions of health education and promotion of breastfeeding. Although pertinent and current, the scientific literature lacks research that explores the topic of breastfeeding from the perspective of the online interaction of mothers, which is a very rich field for future studies.
\end{abstract}

Keywords: Breastfeeding; Health promotion; Internet; Biomedical technology; Maternal and child health.

\title{
Resumen
}

El objetivo de este estudio es sintetizar lo que las madres brasileñas buscan y encuentran en internet sobre lactancia materna, por medio de una revisión crítica de la literatura científica de los últimos 10 años. Los estudios seleccionados permitieron la categorización de tres temas de discusión: calidad de la información disponible; desarrollo de facilitadores para acceso a informaciones sobre lactancia materna y grupos virtuales de apoyo a la lactancia como espacio de educación en salud. La internet es un área con gran potencial para el desarrollo de acciones de educación en salud y promoción de la lactancia materna. A pesar de pertinente y actual, la literatura científica carece de investigaciones que exploren el tema de la lactancia materna desde el punto de vista de la interacción online de las madres, siendo este un campo muy rico para estudios futuros.

Palabras clave: Lactancia materna; Promoción de la salud; Internet; Tecnología biomédica; Salud materno-infantil.

Este artigo faz parte do Dossiê Saúde, etnicidades e diversidade cultural: comunicação, territórios e resistências.

Contribuição dos autores:

Concepção e desenho do estudo: Marina Souto Dalmaso e Andrea Wander Bonamigo.

Aquisição, análise ou interpretação dos dados: Marina Souto Dalmaso.

Redação do manuscrito: Marina Souto Dalmaso.

Revisão crítica do conteúdo intelectual: Marina Souto Dalmaso e Andrea Wander Bonamigo.

Declaração de conflito de interesses: não há.

Fontes de financiamento: não houve.

Considerações éticas: não há.

Agradecimentos/Contribuições adicionais: não há.

Histórico do artigo: submetido: 7 nov. 2018 | aceito: 23 dez. 2019 | publicado: 20 dez. 2019.

Apresentação anterior: não houve.

Licença CC BY-NC atribuição não comercial. Com essa licença é permitido acessar, baixar (download), copiar, imprimir, compartilhar, reutilizar e distribuir os artigos, desde que para uso não comercial e com a citação da fonte, conferindo os devidos créditos de autoria e menção à Reciis. Nesses casos, nenhuma permissão é necessária por parte dos autores ou dos editores. 


\section{Introdução}

O Brasil possui 116 milhões de pessoas conectadas à internet. Uma pesquisa com dados sobre os domicílios brasileiros apontou que 63,3\% das casas no país possuem acesso à rede mundial de computadores. Além disso, proporcionalmente, as mulheres estão mais conectadas em comparação aos homens ${ }^{1}$.

Historicamente, as mulheres preocupam-se mais com sua saúde, se comparado aos homens. A pesquisa nacional mais recente sobre Acesso e Uso dos Serviços de Saúde mostrou que as mulheres procuram mais os serviços de saúde, independentemente do estrato de vulnerabilidade social e da natureza do serviço público ou privado². Pesquisa anterior já apontava que as mulheres comparecem a mais consultas médicas anuais individuais, são maioria nas consultas odontológicas e buscam mais realizar exames preventivos anualmente se comparado aos homens ${ }^{3}$.

Atualmente, todas as mulheres em idade fértil são nascidas e/ou nativas digitais, ou seja, nasceram em um período onde precocemente foram influenciadas e expostas de maneira contínua ao uso de tecnologias. Para essa coorte, a internet tornou-se a plataforma padrão para a busca por conhecimento e como aprimoramento deste hábito, surgiram os agrupamentos com seus pares - grupos virtuais sobre toda e qualquer temática - na tentativa de compartilhar informações, buscar ajuda e suprir a necessidade de validar e respaldar suas ações e decisões ${ }^{4}$.

Os últimos anos foram marcados pela abundância de aplicativos para smartphones na área da saúde constituindo um novo momento da assistência à saúde. As tecnologias móveis de saúde chamadas de $\mathrm{m}$-health oportunizam informações e recursos de monitoramento que servem para aperfeiçoar os resultados e aumentar a adesão ao autocuidado de seus usuários ${ }^{5}$.

Um estudo sobre o perfil do usuário e as tendências de busca mostrou que são das mulheres a maior parte das buscas por informações de saúde na internet. As mulheres também têm maior tendência a compartilhar o resultado de suas buscas e de pesquisar várias vezes o mesmo tema em um mesmo mês ${ }^{6}$.

Esta busca por informações de saúde na internet foi considerada, inclusive, mais intensa do que o ato de realizar compras em sites em um estudo de 2007. Os resultados ainda apontam que 87,33\% das respondentes utilizam a internet para buscar informações de saúde antes ou depois de visitarem seus médicos7 .

Sobre aleitamento materno, um estudo belga apontou que 90,5\% das mulheres respondentes a esta pesquisa revelaram usar a internet para buscar informações sobre si ou sobre o bebê, e o tópico mais pesquisado quanto à saúde da mulher foi o aleitamento materno ${ }^{8}$.

Sendo assim, o objetivo deste estudo foi explorar o que já foi publicado em literatura científica nacional sobre o que buscam as mães brasileiras na internet quando o assunto é aleitamento materno.

\section{Metodologia}

Trata-se de uma revisão crítica da literatura, também conhecida como revisão passiva ou opinativa. A revisão crítica da literatura permite que os autores resumam, opinem e sintetizem as informações disponíveis na literatura científica sem seguir necessariamente uma metodologia predefinida9

O propósito deste estudo em trazer um maior grau de evidência científica não foi plenamente alcançado, vista a escassez de estudos publicados sobre o tema com rigor no delineamento metodológico que culminassem na elaboração de uma revisão integrativa ou sistemática da literatura.

O percurso para a elaboração deste estudo iniciou com a identificação da pergunta norteadora: o que as mães brasileiras buscam e encontram na internet sobre aleitamento materno?

Os descritores definidos para nortear a pesquisa foram 'aleitamento materno', 'mídias sociais', 'internet' e 'Brasil'. Estes termos foram utilizados de forma isolada e em diversas combinações entre os mesmos para ampliar ao máximo o leque de achados, utilizando-se os operadores booleanos 'and' e 'or'. 
O unitermo 'Tecnologias em Saúde' foi acrescido aos descritores pré-selecionados, pois à medida que resumos foram selecionados, observamos que esse termo era mencionado nas palavras-chaves de algumas publicações.

A adoção dos artigos pelo presente estudo passou pelos seguintes critérios: a publicação deveria ter a temática do aleitamento materno e relação com internet e/ou mídias sociais como cerne; data de publicação não superior a 10 anos; as publicações deveriam estar disponíveis em suas versões completas e com resumos disponíveis nas bases de dados PubMed, Lilacs, SciELO, Scopus, DOAJ, Google Scholar e Web of Science.

Por conveniência, também foram buscadas dissertações de mestrado e teses de doutorado na Biblioteca Digital Brasileira de Teses e Dissertações, além de textos completos de eventos científicos e os artigos referenciados nas bibliografias dos estudos encontrados que porventura não foram identificados nas buscas eletrônicas às bases de dados.

Foram excluídos estudos que, após a leitura do resumo, não responderam à pergunta norteadora, objetivo da presente revisão. Foi utilizado o referencial de Minayo e Gomes ${ }^{10}$, para elencar as categorias de análise e discussão após leitura criteriosa dos estudos selecionados.

\section{Resultados}

Foram localizados inúmeros artigos distribuídos nas bases de dados selecionadas, entretanto, houve certa dificuldade, visto que poucos estudos respondiam à pergunta norteadora, outros não se encaixavam na temática do presente artigo, enquanto alguns faziam uso não padronizado de descritores. Ao incluir o descritor 'tecnologias em saúde', por exemplo, percebemos que os estudos utilizam o mesmo descritor tanto para tecnologias leves como folders e acolhimento na atenção básica, como para tecnologias duras, no caso de equipamentos hospitalares, tangenciando os meios digital e virtual que nortearam esta pesquisa.

Dessa forma, optamos pela mineração de estudos nas bases de dados anteriormente citadas com o máximo de combinações possíveis dentre os descritores e ampliamos a busca para teses, dissertações e trabalhos completos em anais, resultando na seleção de nove textos. Os manuscritos selecionados são, em sua grande maioria, oriundos da área da saúde, porém também há um estudo da área da comunicação e um estudo da área da antropologia.

Ressalta-se que esta revisão minerou estudos a partir das palavras-chaves 'amamentação', 'mídias sociais', 'internet' e 'tecnologias em saúde', ou seja, não fez nenhum recorte de gênero, detendo-se a estudos que remetiam apenas a maternidade e experiências maternas. Entretanto, nenhum estudo sobre a busca de informações sobre amamentação do ponto de vista dos pais e da paternidade foi encontrado.

Apesar do recorte metodológico do estudo ser dos últimos 10 anos, os manuscritos selecionados compreendem o período de 2010 a 2017 e estão apresentados no Quadro 1. Trata-se de cinco artigos originais, três dissertações de mestrado e um texto completo disponível em anais de congresso. Os resultados da revisão estão expostos a seguir. 
Quadro 1 - Síntese dos resultados principais dos estudos relacionados ao tema aleitamento materno, internet, mídias sociais e mães brasileiras, elaborada pelas autoras

\begin{tabular}{|c|c|c|c|}
\hline $\begin{array}{l}\text { Autoria, ano de } \\
\text { publicação }\end{array}$ & Tipo de estudo & $\begin{array}{l}\text { Contexto } \\
\text { Mães x Internet }\end{array}$ & Síntese do estudo \\
\hline $\begin{array}{l}\text { Silva e Gubert, } \\
2010\end{array}$ & $\begin{array}{l}\text { Estudo Quantitativo } \\
\text { Descritivo Transversal }\end{array}$ & $\begin{array}{l}\text { Avaliação de } \\
\text { conteúdo de } \\
\text { plataforma digital }\end{array}$ & $\begin{array}{l}\text { Analisou } 103 \text { sites de profissionais da saúde } \\
\text { com informações sobre aleitamento materno e } \\
\text { introdução alimentar, comparando-as com as } \\
\text { recomendações do Ministério da Saúde. }\end{array}$ \\
\hline $\begin{array}{l}\text { Vasconcelos } \\
\text { et al., } 2013\end{array}$ & $\begin{array}{l}\text { Estudo Quantitativo } \\
\text { Descritivo } \\
\text { Transversal }\end{array}$ & $\begin{array}{l}\text { Avaliação de } \\
\text { conteúdo de } \\
\text { plataforma digital }\end{array}$ & $\begin{array}{l}\text { Avaliou, sob a perspectiva do usuário, o } \\
\text { ambiente virtual de aprendizagem 'Aleitamento } \\
\text { Materno do Prematuro', desenvolvido pela } \\
\text { Universidade Federal de Pernambuco. }\end{array}$ \\
\hline Correa et al., 2013 & $\begin{array}{l}\text { Estudo Quantitativo } \\
\text { Descritivo } \\
\text { Transversal }\end{array}$ & $\begin{array}{l}\text { Desenvolvimento } \\
\text { de objeto virtual de } \\
\text { aprendizagem }\end{array}$ & $\begin{array}{l}\text { Revisou e avaliou o conteúdo do site 'Portal } \\
\text { dos Bebês', da Faculdade de Odontologia de } \\
\text { Bauru - SP, quanto às informações sobre } \\
\text { funções orais, incluindo o aleitamento materno. }\end{array}$ \\
\hline Rebecchi, 2015 & $\begin{array}{l}\text { Estudo Qualitativo } \\
\text { Estudo de caso }\end{array}$ & $\begin{array}{l}\text { Participação das } \\
\text { mães em grupos } \\
\text { virtuais }\end{array}$ & $\begin{array}{l}\text { Investigou o compartilhamento de informações } \\
\text { em dois grupos de apoio ao aleitamento } \\
\text { materno no Facebook } 囚 \text {. }\end{array}$ \\
\hline Bati & $\begin{array}{l}\text { Estudo } \\
\text { Metodológico (de } \\
\text { Desenvolvimento) }\end{array}$ & $\begin{array}{l}\text { Desenvolvimento } \\
\text { de objeto virtual de } \\
\text { aprendizagem }\end{array}$ & $\begin{array}{l}\text { Desenvolveu e validou as informações de um } \\
\text { ambiente virtual de aprendizagem 'Amor além } \\
\text { do seio', desenvolvido pela pesquisadora. }\end{array}$ \\
\hline $\begin{array}{l}\text { Monteiro } \\
\text { et al., } 2016\end{array}$ & $\begin{array}{l}\text { Estudo Quantitativo } \\
\text { Descritivo } \\
\text { Comparativo }\end{array}$ & $\begin{array}{l}\text { Avaliação de } \\
\text { conteúdo de } \\
\text { plataforma digital }\end{array}$ & $\begin{array}{l}\text { Analisou } 50 \text { sites e blogs produzidos por leigos } \\
\text { sobre amamentação e introdução alimentar } \\
\text { e comparou com as recomendações do } \\
\text { Ministério da Saúde. }\end{array}$ \\
\hline Cavalcanti, 2016 & $\begin{array}{l}\text { Estudo Qualitativo } \\
\text { Estudo de Caso }\end{array}$ & $\begin{array}{l}\text { Participação das } \\
\text { mães em grupos } \\
\text { virtuais }\end{array}$ & $\begin{array}{l}\text { Relata a interação de mães em um grupo de } \\
\text { mães que possui paralelamente um grupo } \\
\text { virtual no aplicativo WhatsApp } 囚 \text {. }\end{array}$ \\
\hline Nóbrega, 2016 & $\begin{array}{l}\text { Estudo Qualitativo } \\
\text { Estudo de Caso }\end{array}$ & $\begin{array}{l}\text { Participação das } \\
\text { mães em grupos } \\
\text { virtuais }\end{array}$ & $\begin{array}{l}\text { Relatou a interação entre mães em grupo virtual } \\
\text { no aplicativo WhatsApp } ® \text { como uma proposta } \\
\text { de ação educativa sobre aleitamento materno. }\end{array}$ \\
\hline Oliveira et al., 2017 & $\begin{array}{l}\text { Estudo Quantitativo } \\
\text { Transversal } \\
\text { Psicométrico }\end{array}$ & $\begin{array}{l}\text { Desenvolvimento de } \\
\text { tecnologia assistiva }\end{array}$ & $\begin{array}{l}\text { Validou uma tecnologia assistiva sobre } \\
\text { amamentação para educação em saúde de } \\
\text { deficientes visuais. }\end{array}$ \\
\hline
\end{tabular}

Fonte: As autoras (2019).

\section{Discussão}

Vivemos um novo momento na educação em saúde e promoção da saúde, pois se vê o crescente número de usuários de internet no Brasil e uma mudança radical de comportamento dos usuários quando o assunto é saúde. A busca por informações na rede sobre saúde e diagnósticos precede a consulta presencial com profissionais da medicina. Sendo um fenômeno novo, temos um cenário de escassez de produções científicas explorando este tema. Observa-se que a produção científica sobre a relação das mães brasileiras com a internet na temática do aleitamento materno não acompanhou a profusão nas mídias sociais de grupos de apoio e de trocas de experiência sobre maternidade.

A leitura crítica dos trabalhos selecionados resultou na concepção de três categorias de análise: 1) Qualidade das informações disponíveis; uma vez que estudos buscaram avaliar a confiabilidade e a qualidade das informações divulgadas na internet quanto ao tema Aleitamento Materno, buscando consonância com as diretrizes da Organização Mundial da Saúde (OMS) e Ministério da Saúde; 2) Desenvolvimento de facilitadores para acesso a informação sobre Aleitamento Materno, revisando estudos que divulgam na 
comunidade científica a elaboração e a validação de tecnologias leves para a difusão de informações sobre o tema; e 3) Grupos virtuais de apoio à amamentação como espaço de educação em saúde, com análise da participação de nutrizes em grupos virtuais ou aplicativos de trocas de mensagens. O quadro abaixo (Quadro 2) apresenta os manuscritos utilizados na composição de cada categoria.

Quadro 2 - Síntese da composição das categorias de discussão desta revisão, elaborada pelas autoras.

\begin{tabular}{|c|c|c|}
\hline $\begin{array}{l}\text { Autoria, ano de } \\
\text { publicação }\end{array}$ & Título da obra & $\begin{array}{l}\text { Composição nas categorias de } \\
\text { discussão da revisão }\end{array}$ \\
\hline Silva e Gubert, 2010 & $\begin{array}{l}\text { Qualidade das informações sobre aleitamento } \\
\text { materno e alimentação complementar em } \\
\text { sites brasileiros de profissionais de saúde } \\
\text { disponíveis na internet }\end{array}$ & Qualidade das informações disponíveis. \\
\hline $\begin{array}{l}\text { Vasconcelos } \\
\text { et al., } 2013\end{array}$ & $\begin{array}{l}\text { Avaliação de um ambiente digital de } \\
\text { aprendizagem pelo usuário }\end{array}$ & $\begin{array}{l}\text { Qualidade das informações disponíveis e } \\
\text { Desenvolvimento de facilitadores para acesso } \\
\text { a informações sobre Aleitamento Materno. }\end{array}$ \\
\hline Correa et al., 2013 & $\begin{array}{l}\text { Website Babies Portal: development and } \\
\text { evaluation of the contents regarding orofacial } \\
\text { functions. Journal of Applied Oral Science }\end{array}$ & $\begin{array}{l}\text { Qualidade das informações disponíveis e } \\
\text { Desenvolvimento de facilitadores para acesso } \\
\text { a informações sobre Aleitamento Materno. }\end{array}$ \\
\hline Rebecchi, 2015 & $\begin{array}{l}\text { Grupos de apoio ao aleitamento materno } \\
\text { no Facebook: Informação e possibilidade de } \\
\text { emancipação materna }\end{array}$ & $\begin{array}{l}\text { Grupos virtuais de apoio à amamentação } \\
\text { como espaço de educação em saúde. }\end{array}$ \\
\hline Batista, 2016 & $\begin{array}{l}\text { Construção e validação de um website } \\
\text { educativo para promoção da amamentação e } \\
\text { prevenção de hábitos orais deletérios }\end{array}$ & $\begin{array}{l}\text { Qualidade das informações disponíveis e } \\
\text { Desenvolvimento de facilitadores para acesso } \\
\text { a informações sobre Aleitamento Materno. }\end{array}$ \\
\hline $\begin{array}{l}\text { Monteiro } \\
\text { et al., } 2016\end{array}$ & $\begin{array}{l}\text { Assessing the nutritional information for } \\
\text { children younger than two years old available } \\
\text { on popular websites }\end{array}$ & Qualidade das informações disponíveis. \\
\hline Cavalcanti, 2016 & $\begin{array}{l}\text { Grupo Papo de Mãe: uma experiência de rede } \\
\text { de apoio à maternagem em Belém do Pará }\end{array}$ & $\begin{array}{l}\text { Grupos virtuais de apoio à amamentação } \\
\text { como espaço de educação em saúde. }\end{array}$ \\
\hline Nóbrega, 2016 & $\begin{array}{l}\text { As redes sociais de apoio ao aleitamento } \\
\text { materno: uma pesquisa-ação }\end{array}$ & $\begin{array}{l}\text { Qualidade das informações disponíveis e } \\
\text { Grupos virtuais de apoio à amamentação } \\
\text { como espaço de educação em saúde. }\end{array}$ \\
\hline Oliveira et al., 2017 & $\begin{array}{l}\text { Amamentação: validação de tecnologia assistiva } \\
\text { em áudio para pessoa com deficiência visual }\end{array}$ & $\begin{array}{l}\text { Desenvolvimento de facilitadores para acesso } \\
\text { a informação sobre Aleitamento Materno. }\end{array}$ \\
\hline
\end{tabular}

Fonte: As autoras (2019).

\section{Qualidade das informações disponíveis}

A Organização Mundial da Saúde (OMS) recomenda o aleitamento materno exclusivo (AME) até os seis meses, sem a necessidade de introdução de qualquer outro alimento neste período ${ }^{11}$. A partir do $6^{0}$ mês, recomenda-se seguir o aleitamento até os dois anos ou mais concomitante à oferta de outros alimentos de forma complementar, uma vez que o leite materno já não é mais suficiente para a nutrição do bebê. Esta recomendação é reiterada pelo Ministério da Saúde por meio de inúmeras publicações legais sobre aleitamento materno, saúde materno-infantil ou de nutrição infantil, dentre eles o Guia Alimentar para crianças menores de dois anos e a Estratégia Amamenta e Alimenta Brasil12,13.

Existe a expectativa de que toda a iniciativa de promoção do aleitamento materno e educação em saúde em prol da amamentação ratifiquem a OMS. Um estudo que avaliou o conteúdo sobre aleitamento materno de 103 sites de instituições de saúde e profissionais da saúde revelou que o AME até o $6^{\circ}$ mês é recomendado em apenas 64,1\% dos sites. Nos demais 35,9\% destas páginas não havia menção sobre a duração do AME. 
Ainda que não recomendassem a interrupção do AME antes do preconizado, a omissão desta informação por 1/3 dos sites pesquisados pode levar aos usuários que as acessam à desinformação e invariavelmente à introdução precoce de outros alimentos ${ }^{14}$. Uma vez que estes sites são de profissionais da saúde e/ou instituições de saúde e foram concebidos com o objetivo de informar a população e promover a saúde com ênfase no apoio e incentivo ao AM, é necessário que haja um empenho maior e responsabilidade dos mesmos em atualizar-se e serem norteados pelas publicações oficiais vigentes.

Outra pesquisa avaliou 50 sites populares, comparando seu conteúdo com o referencial teórico do Guia alimentar para crianças menores de dois anos do Ministério da Saúde, principal e mais atualizada publicação sobre nutrição infantil 12,15. O guia recomenda 10 passos para a alimentação saudável, dentre eles "dar somente leite materno até os seis meses, sem oferecer água, chás ou qualquer outro alimento”. Dos 50 sites selecionados, 41 deles (82\%) apresentavam a informação correta que o AME deve ser até os seis meses, entretanto ainda havia oito sites que divulgavam erroneamente que o AME deve ser até os quatro meses, quando se pode iniciar a introdução de chá e água. A introdução de chás e água antes do sexto mês tem grande valor cultural, pois as mães acreditam que os mesmos são nutritivos para seus filhos ${ }^{16}$. A II Pesquisa de Prevalência de Aleitamento Materno nas Capitais Brasileiras e Distrito Federal apontou que 15,3\% e 13,8\% dos recém-nascidos com um mês de vida já haviam tido contato com chás e água, respectivamente ${ }^{17}$. Em um estudo no interior do Paraná, $25 \%$ das crianças haviam consumido chá e água no período de AME, ou seja, quando menores de seis meses ${ }^{18}$. A introdução precoce de outros alimentos influencia negativamente na duração do AME e deve ser desaconselhada ${ }^{16}$.

A busca por informações também se dá por meio de grupos virtuais, como na rede social Facebook $₫$ e no aplicativo de troca de mensagens instantâneas WhatsApp®, onde é possível não só esclarecer dúvidas, mas também compartilhar experiências e modos de fazer. Entretanto, quando se trata destes grupos virtuais, há de se considerar que não há só contato com experiências exitosas baseadas em evidências científicas, mas também há a transmissão de crenças, mitos e tradições enraizados no contexto em que se vive, os quais muitas vezes diferem das recomendações atuais e também experiências frustradas que resultaram em desmame precoce ou orientação quanto ao uso de bicos artificiais de forma indiscriminada19. Mesmo com a evidência científica de que o uso de bicos artificiais é fator de risco para desmame precoce ${ }^{20}$, apenas 1/3 das páginas avaliadas em um estudo apresentava a recomendação de não ofertar chupetas e mamadeiras para os bebês ${ }^{15}$.

Neste estudo ${ }^{21}$, um site foi desenvolvido por uma cirurgiã-dentista para promoção do aleitamento materno, da saúde bucal e também de informações sobre hábitos orais deletérios para a Atenção Básica. O mesmo passou por validação de seis juízes de conteúdo e três juízes de aparência, das áreas de Enfermagem, Odontologia e Tecnologia, garantindo que o site possui credibilidade nas informações, além de ludicidade e fácil interação na navegação.

Não só publicar recomendações validadas, mas avaliar forma e conteúdo é de suma importância. $\mathrm{Na}$ construção de um site sobre funções motoras orais em um portal de Odontologia, a análise de conteúdo foi feita tanto por profissionais da saúde (fonoaudiólogos) quanto pelo público-alvo, os pais. O conteúdo foi baseado em publicações científicas seguindo as recomendações do Ministério da Saúde, porém foi reescrito em linguagem acessível para atingir o maior número de pessoas ${ }^{22}$.

\section{Desenvolvimento de facilitadores para acesso à informação sobre Aleitamento Materno}

A criação de recursos digitais para a promoção da saúde é crescente. O desenvolvimento de sites, aplicativos, objetos virtuais de aprendizagem e tecnologias assistivas é uma tendência mundial, principalmente sob os olhos do empreendedorismo social e da qualificação do processo de trabalho em saúde. Novos recursos provêm da produção de conhecimento científico, da qualificação do cotidiano assistencial e da necessidade de promover acessibilidade ${ }^{23}$.

Na confecção de um site sobre cuidados com bebês prematuros, as autoras de um estudo buscaram a validação do conteúdo e da plataforma utilizada por meio da avaliação das usuárias - mães de bebês 
prematuros $^{24}$. Os assuntos abordados perpassavam temas sobre prematuridade, as dificuldades do recémnascido pré-termo em sugar a mama e a manutenção da produção láctea durante a internação do bebê em UTI Neonatal até o retorno para casa. 76,7\% das usuárias consideraram que o site trouxe aprendizado e que esta tecnologia pode facilitar a aquisição de informações sobre aleitamento materno.

Para o desenvolvimento de um website sobre amamentação e saúde bucal ${ }^{21}$, a autora recorreu a sucessivas etapas até distribuir o conteúdo. A metodologia do desenvolvimento deste ambiente incluiu a realização de dois grupos focais, com mães e gestantes, para minerar quais conteúdos seriam relevantes para disponibilizar no website.

Outro ambiente virtual foi desenvolvido e avaliado por meio de um estudo que foi conduzido em três etapas: a pesquisa na literatura científica e atual sobre o tema funções miofuncionais orais, dentre elas o aleitamento materno; a adaptação da linguagem científica para uma linguagem mais simples e acessível para um público diversificado; e a avaliação do site por fonoaudiólogos e pais. O site em questão foi considerado uma ferramenta com adequado nível de legibilidade e contribuiu para o acesso a novos conhecimentos sobre o tema ${ }^{22}$.

É de extrema relevância que o público-alvo destas iniciativas seja consultado, tanto na elaboração do conteúdo ${ }^{21}$ como na avaliação do resultado final ${ }^{22}$.

A inserção de tecnologias de informação e comunicação na promoção do aleitamento materno, já realizada pelos profissionais da saúde na assistência à mulher gestante e puérpera, pode trazer contribuições positivas, porém ainda não há estudos que comprovem o efeito destas intervenções no aumento da prevalência e duração do aleitamento materno ${ }^{23}$.

O desenvolvimento de tecnologias assistivas vem para incrementar os recursos de promoção da saúde, visando atender a população de pessoas com deficiência que ainda carece de acesso aos serviços como um todo, incluindo o contexto da saúde. Iniciativas como a da criação de um cordel cantarolado para orientar o aleitamento materno a mulheres com deficiência visual traz equidade nos espaços de educação em saúde para amamentação, pois inclui uma tecnologia assistiva disponível on-line com qualidade de informação, avaliada por deficientes visuais como interessante, atrativa, clara, instrutiva e de tom amigável ${ }^{25}$.

Nenhum estudo brasileiro foi encontrado relatando experiências de promoção de aleitamento materno às mães deficientes auditivas. Faz-se necessário ampliar a discussão a respeito do desenvolvimento de tecnologias assistivas como alternativa viável e necessária para a promoção da saúde como um todo.

\section{Grupos virtuais de apoio à amamentação como espaço de educação em saúde}

Cada vez mais frequentes e numerosos, os grupos virtuais utilizando a plataforma Facebook $₫$ ou o aplicativo para troca de mensagens espontâneas WhatsApp $®$ tornam-se espaço em validação de educação em saúde. Nestes espaços, ao serem estimulados a falar de si mesmos, os usuários constroem seus próprios perfis a partir do que expressam de sua personalidade e da interação que fazem com outras pessoas ${ }^{26}$.

No caso de gestantes e lactantes, o ingresso nestes grupos proporciona a sensação de pertencimento, pois elas encontram apoio em seus pares e transformam suas virtudes, até então individuais, em saber disponível e coletivo. Em um estudo sobre grupos de apoio ao aleitamento materno no Facebook®, a autora percebeu que as usuárias buscavam não só resolver seus problemas, mas auxiliar outras usuárias em suas dificuldades, em uma rede de reciprocidade e confiabilidade ${ }^{27}$.

A reciprocidade também foi citada em outro estudo, que criou um grupo no WhatsApp $®$ como extensão de um grupo de gestantes presencial de uma Estratégia de Saúde da Família. A autora utilizou a Teoria da Dádiva para definir o sentimento de dar algo de si enquanto recebe algo do outro. As trocas realizadas no grupo foram além das informações sobre aleitamento materno, pois a interação fortaleceu os vínculos já criados dentro do espaço físico da unidade de saúde e criou uma identidade coletiva para aquele grupo de mulheres ${ }^{19}$. 
Ainda que se fale de emancipação feminina como um produto desta interação, situações como imposição de limites nas postagens e opiniões discordantes são comuns e devem ser discutidas. A autora de uma pesquisa percebeu que ao mesmo tempo em que o grupo permitiu acesso à informação, trocas de experiências e consequente empoderamento da mulher na temática do aleitamento materno, havia uma submissão por parte das usuárias e moderadoras dos grupos às normas da Organização Mundial da Saúde. Notou-se que a individualidade nem sempre era respeitada em detrimento do controle das informações compartilhadas e, quando havia questionamento, as mulheres tinham suas condutas criticadas, eram aconselhadas a mudar suas práticas, não permitindo o acolhimento de opiniões e saberes individuais além do pensamento hegemônico ${ }^{27}$.

A moderação do grupo também foi discutida em um estudo envolvendo um grupo de WhatsApp® que possuía a administração de uma profissional da saúde em comum a todas as usuárias, que intervinha no debate de forma mais ativa, restringindo alguns tipos de conteúdo como emissão de opinião pessoal sobre outros profissionais da saúde ${ }^{28}$. A figura do moderador é um elemento essencial e de promoção de interação e inclusão de todos os participantes no debate de modo que o conhecimento construído coletivamente seja replicável por cada um em seus diferentes contextos. Seu posicionamento deve contribuir para que a comunidade se torne um espaço dialógico que respeite a multiplicidade de saberes e permita a construção de uma identidade do grupo 29 .

Nesses momentos é importante ressaltar o papel fundamental do mediador do grupo para mediarem os conflitos e tensionamentos que surgem na discordância de opinião, informar o regramento para realização de postagens ou no tangenciamento dos temas em debate.

Um recente estudo avaliou o tipo de apoio que aplicativos pró-amamentação oferecem e concluiu que a maioria dos aplicativos disponíveis era apenas para consultas informativas ${ }^{30}$. Embora o acesso à informação fácil pela internet possa beneficiar estas mães, a informação por si só pode não ser suficiente para produzir um desfecho favorável no tempo de aleitamento. Os autores acreditam que aplicativos que promovem troca de mensagens ao vivo podem levar a maior engajamento à amamentação. Essa disponibilidade de uma rede de apoio 24h no exato momento da dúvida ou necessidade trouxe segurança para o ato de amamentar em si e fortaleceu o vínculo das mães e os profissionais da saúde de uma Unidade da Atenção Básica, conforme pesquisa desenvolvida na região metropolitana de Natal - RN19.

Os grupos virtuais podem ser considerados espaços de acolhimento, humanização das relações e acesso à educação em saúde ${ }^{19}$. Para a autora deste estudo, entretanto, ainda não temos comprovação científica de que estas alternativas impactem positivamente nos indicadores de saúde sobre tempo de aleitamento materno. Em uma revisão sistemática da literatura sobre a eficácia das ações na internet nos desfechos no aleitamento materno, não foi possível recomendar a internet como uma fonte eficaz de apoio à amamentação pela inexistência de estudos com boa amostragem e rigor metodológico, apesar de abundantes estudos na área terem sido elencados ${ }^{31}$.

\section{Conclusão}

A Era Digital trouxe não só o acesso à informação mais fácil como também a necessidade do imediatismo. A democratização do acesso à internet e a aquisição de smartphones fizeram com que tivéssemos acesso a qualquer coisa de qualquer lugar, criando a necessidade de que tudo seja feito no menor tempo possível.

É notório que há uma crescente tendência pela busca de informação sobre saúde na internet, aplicativos e mídias sociais, uma vez que estas informações são ligeiramente atualizadas e estão $24 \mathrm{~h}$ disponíveis para consulta. As mídias sociais, em especial o Facebook $₫$ e WhatsApp $®$, têm enorme potencial didático e pedagógico no que diz respeito à educação em saúde.

A segurança das informações encontradas, a busca por respaldo do que é orientado por profissionais da saúde e a troca de mensagens em grupos podem ser benéficos do ponto de vista da celeridade e do acesso à informação, porém deixam as pessoas em alerta sobre o tipo de informação sendo compartilhada. 
Entende-se que é necessário considerar as particularidades e singularidades de cada um, bem como a forma individual com que cada sujeito compreende as informações acessadas dentro de sua visão de mundo.

As mídias sociais são espaços democráticos e socializados de autoconstrução. Todas as atitudes relativizadas e tomadas pelas mães visam a um ciclo saudável de aleitamento materno e, mesmo na discordância atitudinal frente à recomendação da OMS, não necessariamente ter-se-á uma experiência de amamentação malsucedida. Cabe ao administrador do grupo ou pessoa responsável pelo debate mediar estes conflitos de forma que todo posicionamento seja acolhido com respeito e empatia.

A gama de informações sobre amamentação na internet é enorme e deve-se orientar as mulheres a buscar informações dentro de portais que possuam respaldo técnico, como as publicações legais do Ministério da Saúde voltadas para o público leigo. Além disso, a crescente popularidade das redes sociais oferece oportunidade aos profissionais da saúde para criar intervenções de saúde inovadoras e acessíveis para a promoção da amamentação.

O desenvolvimento de objetos virtuais de aprendizagem que garantam acessibilidade para mães e pais com deficiências foi uma grata surpresa deste estudo, ainda que não tenhamos encontrado dentro da literatura científica a publicidade de iniciativas para a promoção do aleitamento materno entre os deficientes auditivos, tanto oralizados quanto sinalizados.

A literatura científica carece de pesquisas que explorem o tema do aleitamento materno sob o ponto de vista da interação on-line das mães, sendo este um campo muito rico para estudos futuros. A internet e as mídias sociais, bem como objetos de aprendizagem e aplicativos dedicados à saúde da mulher no ciclo gravídico-puerperal, devem ser exploradas pelo enorme potencial que possuem para o desenvolvimento de ações de educação em saúde e promoção do aleitamento materno.

\section{Referências}

1. IBGE. Pesquisa Nacional por Amostra de Domicílios: Acesso à internet e à televisão e posse de telefone móvel celular para uso pessoal. Rio de Janeiro: Coordenação de Trabalho e Rendimento; 2016. 87 p.

2. Barata RB. Acesso e uso de serviços de saúde: considerações sobre os resultados da Pesquisa de Condições de Vida 2006. São Paulo em perspectiva. 2008; 22(2):19-29.

3. Pinheiro RS, Viacava F, Travassos C, Brito AdS. Gênero, morbidade, acesso e utilização de serviços de saúde no Brasil. Ciênc. Saúde Coletiva. 2002;7:687-707.

4. Weatherspoon D, Weatherspoon C, Ristau C. Speaking Their Language: Integrating Social Media into Childbirth Education Practice. Int J Childbirth Educ. 2015; 30(2):21-4.

5. Barra DCC, Paim SMS, Sasso GTMD, Colla GW. Métodos para desenvolvimento de aplicativos móveis em saúde: revisão integrativa da literatura. Texto Contexto Enferm. 2017;26(4):1-12.

6. Moretti FA, Oliveira VE, Silva EMK. Acesso a informações de saúde na internet: uma questão de saúde pública? Rev. Assoc. Méd. Bras. 2012;58:650-8.

7. Carvalho RB, Alves MV, Jamil GL, Carvalho JA. Análise do comportamento de consumo virtual e acesso à internet de mães brasileiras. Rev Pretexto. 2007;8(3):53-74.

8. Slomian J, Bruyere O, Reginster JY, Emonts P. The internet as a source of information used by women after childbirth to meet their need for information: A web-based survey. Midwifery. 2017;48:46-52.

9. Mancini MC, Sampaio RF. Quando o objeto de estudo é a literatura: estudos de revisão. Braz J Phys Ther. 2006;10(4).

10. Minayo MCS, Gomes SFDR. Pesquisa social: teoria, método e criatividade. 34 ed. Petrópolis: Vozes; 2012.

11. Victora CG, Bahl R, Barros AJD, França GVA, Horton S, Krasevec J et al. Breastfeeding in the 21st century: epidemiology, mechanisms, and lifelong effect. The Lancet. 2016;387(10017):475-90.

12. Ministério da Saúde (BR). Guia alimentar para a população brasileira. 2. ed. Brasília: Ministério da Saúde; 2014. 
13. Ministério da Saúde (BR). Portaria No 1.920, de 5 de setembro de 2013. Institui a Estratégia Nacional para Promoção do Aleitamento Materno e Alimentação Complementar Saudável no Sistema Único de Saúde (SUS) - Estratégia Amamenta e Alimenta Brasil. Brasília: Ministério da Saúde; 2013.

14. Silva RQ, Gubert MB. Qualidade das informações sobre aleitamento materno e alimentação complementar em sites brasileiros de profissionais de saúde disponíveis na internet. Rev Bras. Saúde Mater. Infant. 2010;10(3):331-40.

15. Monteiro GSG, Assis MM, Leite MA, Mendes LL. Assessing the nutritional information for children younger than two years old available on popular websites. Rev. Paul. Pediatr. 2016;34(3):287-92.

16. Schincaglia RM, Oliveira AC, Sousa LM, Martins KA. Práticas alimentares e fatores associados à introdução precoce da alimentação complementar entre crianças menores de seis meses na região noroeste de Goiânia. Epidemiol. Serv. Saúde. 2015;24(3):465-74.

17. Ministério da Saúde (BR). II Pesquisa de Prevalência de Aleitamento Materno nas Capitais Brasileiras. Brasília: Ministério da Saúde; 2009.

18. Saldan PC, Venancio SI, Saldiva SRDM, Pina JC, Mello DF. Práticas de aleitamento materno de crianças menores de dois anos de idade com base em indicadores da Organização Mundial da Saúde. Rev. Nutri. 2015;28(4):409-20.

19. Nobrega VCFD. As redes sociais de apoio ao aleitamento materno: uma pesquisa-ação. Natal: Universidade Federal do Rio Grande do Norte; 2016.

20. Buccini GS. Evolução do uso de chupeta e sua influência no aleitamento materno exclusivo no Brasil, 19992008 [tese]. São Paulo: Universidade de São Paulo; 2017. 170 p.

21. Batista RRS. Construção e validação de um website educativo para promoção da amamentação e prevenção de hábitos bucais deletérios [dissertação]. Ceará: Universidade Federal do Ceará; 2016. 192 p.

22. Correa CC, Pauleto ARC, Ferrari DV, Berretin-Felix G. Website Babies Portal: development and evaluation of the contents regarding orofacial functions. J Appl Oral Sci. 2013;21(6):581-9.

23. Silva NVN, Pontes CM, Sousa NFC, Vasconcelos MGL. Tecnologias em saúde e suas contribuições para a promoção do aleitamento materno: Revisão integrativa da literatura. Ciênc. Saúde Coletiva. 2019;24(2):589-602.

24. Vasconcelos MGL, Góes FdSN, Fonseca LMM, Ribeiro LM, Scochi CGS. Avaliação de um ambiente digital de aprendizagem pelo usuário. Acta Paul. Enferm. 2013;26(1):36-41.

25. Oliveira PMP, Pagliuca LMF, Cezario KG, Almeida PC, Beserra GL. Amamentação: validação de tecnologia assistiva em áudio para pessoa com deficiência visual. Acta Paul. Enferm. 2017;30(2):122-8.

26. Pisa LF. O perfil do Facebook visto pelo poder, discursos e subjetividades. Ling Acadêmica. 2014;4(1):51-68.

27. Rebecchi A. Grupos de apoio ao aleitamento materno no Facebook: informação e possibilidade de emancipação materna [dissertação]. São Paulo: Faculdade Cásper Líbero; 2015. 125 p.

28. Cavalcanti NCSB. Grupo Papo de Mãe: uma experiência de rede de apoio à maternagem em Belém do Pará. In: Anais da 30a Reunião Brasileira de Antropologia; 3 a 6 de agosto de 2016; João Pessoa. João Pessoa: Editora da ABA; 2016.

29. Lisboa ES, Coutinho CP. O papel do E-moderador em comunidades virtuais: um estudo na rede social Orkut. In: $11^{\circ}$ Simpósio Internacional de Informática Educativa; 18 a 20 de novembro de 2009; Coimbra, Portugal. Coimbra: Repositório da Universidade do Minho; 2009.

30. Schindler-Ruwisch JM, Roess A, Robert RC, Napolitano MA, Chiang S. Social support for breastfeeding in the era of mHealth: a content analysis. J Hum Lact. 2018; 34(3):543-55.

31. Giglia R, Binns C. The effectiveness of the internet in improving breastfeeding outcomes: a systematic review. J Hum Lact. 2014;30(2):156-60. 